\title{
Structure and spatial pattern of land uses patches in the Zagros Mountains region in the west of Iran
}

\author{
ARASH KARAMI ${ }^{1}$, KIOMARS SEFIDI $^{2, \boldsymbol{\varphi}}$, JAHANGIR FEGHHI $^{1}$ \\ ${ }^{1}$ Department of Forestry, Faculty of Natural Resources, University of Tehran, Karaj, Iran \\ ${ }^{2}$ Faculty of Agriculture Technology and Natural Resources, University of Mohaghegh Ardabili, Ardabil, Iran. Tel./Fax.: +98-451-5512081; \\ "email: kiomarssefidi@gmail.com
}

Manuscript received: 28 August 2013. Revision accepted: 18 November 2013.

\begin{abstract}
Karami A, Sefidi K, Feghhi J. 2014. Structure and spatial pattern of land uses patches in the Zagros Mountains region in the west of Iran. Biodiversitas 15: 53-59. Landscape ecology as a new interdisciplinary science, concepts, theories and methods provides for evaluation and management of land. Quantification of landscape patterns has key role in the interpretation and modeling of spatial and chronically variation of land uses. This study carried out in the Zagros vegetative region in the west of Iran to quantify structure and spatial pattern of land uses and forest fragmentation in the Zagros Mountains region. The mosaic analysis method was used for quantifying landscape metrics. Totally 2783 land use patches were recorded in the study area. The most of the patches were agricultural area and the lowest number of patches recorded for rivers. Diversity indices analysis showed agricultural land use has highest diversity in comparing with other land uses. Rangeland use has distributed in the central region of the study area. Despite the high density agriculture and rangeland a lot of potentials there are two conversions this land as a sustainable ecosystem (forests, agriculture integrated, and rangelands), that can be by applying as an appropriate method in management and control policies and converting artificial land uses to the natural or semi natural land uses according to the advantages of such land uses in view of sustainability. We conclude that fragmentation of natural land uses such forest and rangelands should be reducing and maintain large patches of natural vegetation to sustainable land management in this region.
\end{abstract}

Key words: Metrics, FRAGSTATS, Iran, land use, landscape ecology

\section{INTRODUCTION}

Human development since its presence on this planet was life on natural resources, and intervention in natural ecosystems and the domestication of plants and animals on the planet. Human economical activities are mainly in landscape scale, so the landscape is appropriate spatial scales for the study of environmental change is a result of human activities. Eventually all human activities lead to land use location and structure changes, so landscapes provide a reflection of past human land use and as alive and dynamic framework for sustainable land use are imposed (Xiao and Zhong 1998). There are many similarities between the structure of landscape, land use structure, function of landscape, land use changes and changes in landscape, but the primary goal of ecological studies in all the land is landscape (Naveh and Liberman 1984). Development landscape ecology provides a suitable theoretical basis to study land use changes. When the connection between landscape ecology and sustainable development has been created, principles ecological landscape as the main concepts related to sustainable land use is proposed. Obviously, in areas where land management (land use) with the potential ecological imbalance, must provide reasonable and practical solutions to resolve this inconsistency, and the severity of the imbalance is greater, in terms of management reform, has high priority. The first step in planning is knowledge. Knowing the current situation, awareness of process and forecasting the future is base of planning in the landscape management. To determine the status of land management and land use in different areas and compare them together, to set redundancy between optimal and the current situation, can move towards sustainable development and appropriate land. Landscape ecology is strongly associated with land use, particularly which this relationship of aspects the spatial patterns as is made of land use planning and management it the foundation ( $\mathrm{Wu} 2000$ ). According to the landscape ecology principles analysis of spatial and structural characteristics of land use patches has key role in the interpretation and modeling of spatial and chronically variation of land uses (Wegener 1994; Herzog and Lausch 2001). Besides studying the structure according to principles of ecology, quantitative metrics of landscape appropriate suitable tools for quantifying the spatial characteristics of the components of the landscape. Concepts of landscape ecology can be expanded in planning for land use management in order to reduce the negative effects of human manipulations in land using (Lausch and Herzog 2002).

As mentioned, landscapes are strongly changing. In monitoring the areas and landscape changes in the position and applications of various lands should be considered. This information can be very useful for users, designers 
and managers in land use managing (Zhang and Ni 2001). Landscapes metrics can consider as algorithms for quantifying the spatial characteristics of patches, classes or landscape whole patches metrics, Metrics with the ecological principles of landscape and interpret it are as the best way to compare the situation of landscape in different lands. These metrics also can be considered as comparative tools to analysis different landscape scenarios or obtain knowledge about landscape land situation changes over time. Meanwhile, such metrics can be used for the design and find an accurate relationship between the structure and function in landscapes (Botequilha-Leitão et al. 2006). According to the given concepts, in this paper has tried to work on landscape ecology, In order to quantify and interpret the location and structure for sustainable land and reduce them to be considered unstable, until damage and easy loss (fragmentation) of these complex patterns to be normal.

The most regions of Iran because of the ecological richness and genetic resources have high ecological value, but in Zagros region because of the of high biodiversity, genetic conditions, cultural, and social climate of the region and particularly on the specific structure of tribal life, traditional economy based on agriculture and animal husbandry and as a result dependence of livelihoods on natural resources management, planning for sustainable and appropriate utilization of these resources are necessary. Therefore it was necessary for greater recognition and status for different regions, the research done in this area.

Thus, the goal of this research was to analysis the position of different land use from each other and try to find how located them in the context of Landscape. Quantify the structure and characteristics of ecosystem as an ecological analysis and understanding the different ecosystems function(among different land use) are basis for comparison how effects of human and environmental changes in overtime on land use(Bell 1999).Also in this research composition and spatial distribution of structural elements in the landscape had studied, that their main role is in improvement ecological functions of the study area, and what corrective actions can cause improvements in ecological structure and in result processes associated with them will be discussed. In other word the main goal of this research we are interested to quantify the information on fragmentation of natural land uses in the Zagros Mountains region in the west of Iran. The specific objectives were calculating spatial pattern of land use patches including: number of patches (NP), land area fraction by patches (PLAND), patch density (PD) and Shannon's diversity index (SHDI) in class and landscape levels

\section{MATERIALS AND METHODS}

\section{Study area}

This study was conducted in the Zagros Mountains region in the west of Iran. Kurdistan province is located in the northern Zagros Mountains in the west of Iran (latitude range in: 34०, 44० 36, $30 \mathrm{~N}$; longitude range: $31 \circ-45 \circ$, 48, $16 \mathrm{E})$. Territory of Zagros Mountains region is now one of the oldest sources of biodiversity and the one of the first settlement place of the Iranian people (Razmara 2005). According to meteorological statistics, Zagros Mountains region has a semi-humid climate with very cold winters and the Alpine and average annual rainfall is $512 \mathrm{~mm}$, that volume equivalent to14 billion cubic meters annually it is estimated (Anon. 2000). Based on vegetation maps produced about $60 \%$ the total area of the Zagros Mountains region have is vegetation cover forest and pasture. In this province due to geographical environment diversity, and uneven condition of weather conditions, land use different types can be observed, but land use with cover forest and pasture associated with species of Quercus persica, Quercus libani, Quercus infectoria, Crataegus aronia, Pistacia mutica, Amygdalus communis, Cotoneaster spp. and also grass species such Salvia eremophila, Ferula ovina, Achillea wilhelmsii, Vicia sativa and etc. with the highest level and use the region and the species that of plant specific species are considered to these areas (Marvie-Mohadjer 2005). The region soil of type soil rocks with a schist bed rock of type brown calcareous and in the mountains and edges are Rendzine. Agriculture land use focuses more on the west the province (Figure 1). In the last decades construction and developing of new land uses by human in towns and villages across the province led to the have been a creation specific type of land use called the forestry-agriculture-livestock, that need to multipurpose managing lands in 'agroforestry' systems also use more participate of local people in this area (Shamekhi 2007).

\section{Procedures}

This research had carried out in three scales including patches, classes (zones) and Landscape (McGarigal and Marks 1994). The bases of our study were support and maintain more valuable patches and increase convergence of sustainable patches.

In this study we used maps of land use created by the Iran Organization of Forests, Range and Watershed Management (IOFPWM) were prepared using the accurate geostatistics for the total Iran in 2010, It should be mentioned that this map is based on purposes the researcher reclassified and six categories including: the forest defined as land with tree crown cover or equivalent crown canopy level of more than 5 percent and area of more than 0.5 ha, pastures including rangelands and pastures, agricultural lands, no coverage and bare land (e.g. Arid and salty soil land), residential areas and Rivers (e.g. Rivers and canebrake).

The approach used in this research was based on landscape ecology, in this approach, the relationship between structure and function of process-scale approach is landscape had considered (Botequilha-Leitao and Ahren 2002). Using this approach and its method and techniques, are known as series disruption of ecosystems related to each other, one effective method is considered for ecological analyzing the area (Ingegnoli 2002). Afterward spatial structure and analysis of different metrics of patches was quantified using FRAGSTATS 3.3software (McGarigal and Marks 1994). FRAGSTATS is a Spatial Pattern Analysis Program and complete set of landscape metrics. 


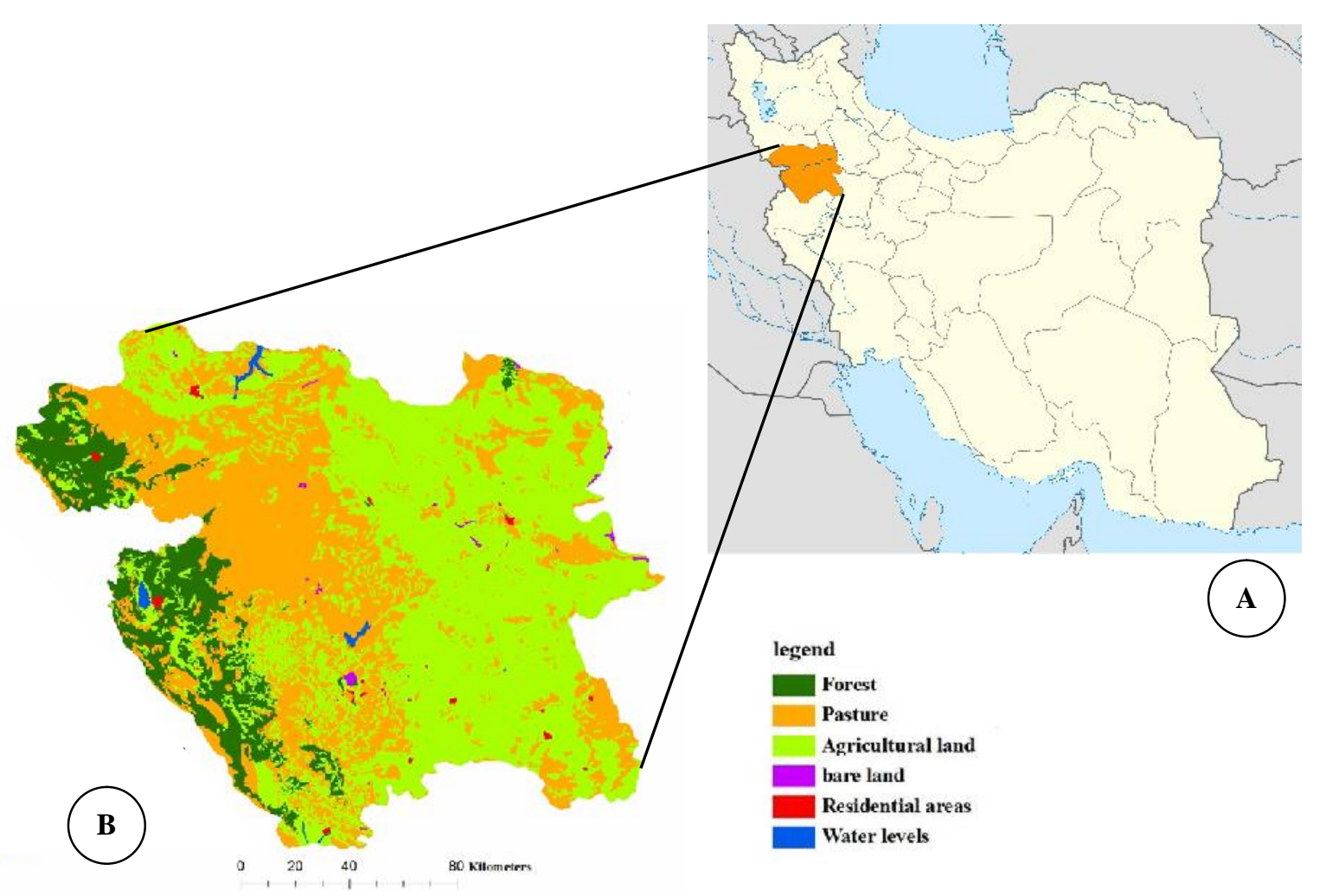

Figure 1A. Location of the study area in the west of Iran. B. Map of land use Kurdistan province (Forests, Range and Watershed management Organization, I.R. Iran (2010) and reclassified by Karami (2011).

This program does not create restrictions on the scale and is suitable software for spatial patterns and various metric landscape patches analyzing that make up the territory in a heterogeneous environment and is suitable in different conditions. The FRAGSTATS ARC software is used to demonstrate the linkage of the U.S. Forest Service's FRAGSTATS program to the Arc Info GIS (ESRI 1992) which is updated version of the USDA Forest Service General Technical Report PNW-GTR-351. In this research metrics have been calculated according to the purposes in meter or hectare. For each input to FRAGSTATS software, 3 outputs file is created. The file named Patch, Class and the Land as a text file and all files are visible. These tools to analyze spatial patterns, especially in modeling habitat; wildlife protection and forest management are applied. Ability to describe a quality of landscape, a prerequisite is for studying the function and change the landscape, and different metric to achieve this goal; the ecology has been extracted from landscape, for example the application model provided by a Foreman landscape focuses on four models for the sustainable planning (McGarigal and Mark 1995) including (i) Maintain large patches of natural vegetation, (ii) maintenance of wide river corridors, (iii) maintains the continuity of key species among large patches and (iv) maintaining the heterogeneous parts of natural human development in the region. In this study before to data entering operation in FRAGSTATS software, we needed to prepare the data in the IDRISI software, because of raster format of data on Zagros
Mountains land use maps. In relation to some of the landscape metrics that were used in this research, we had defined metrics as shown in Table 1. Some metrics are the standard metrics of FRAGSTATS but some of them such as standard deviation of neighbor distance used in analysis fragmentation of land use patches.

\section{Data analysis}

We analyzed data in two different levels: (i) metrics analysis in class level to calculate land use Changes in similar land use patches and (ii) metrics analysis at the landscape level to calculate land use total patches in the entire study area.

\section{Class analysis}

At this level there are 6 classes included Forest, Rangelands, Agricultural area, bare land, Residential area and Rivers which metrics were calculated for each class. The metrics used in this level included: The mean shape index (MSI), number of patches in class level (NP) which used to calculate the number of patches in each class. Largest patch indexes (LPI), largest patches in each class were calculated. Patch density (PD), Density of patches per class per unit area was calculated. Edge density (ED) and Total edge (TE).

Also the length strips around each land use and complexity of it calculated. Class area (CA), the area covered by each class had calculated. Characteristic of the Euclidean distance between patches include (ENN_MN, 
ENN_AM, ENN_MD, ENN_RA, ENN_SD and ENN_CV). Metric related Statistics including mean, median, range, standard deviation and coefficient of variation had calculated between patches. We should be mentioned McGarigal and Marks (1994) note that the value of the Fractal dimension as computed in FRAGSTATS is dependent upon the patch size and the units used (Rogers 1993).

\section{Landscape analysis}

Metrics analysis at landscape level was done with calculating metrics of total land use patches. For analysis Metric of at the landscape level, in addition, using metrics that mentioned in class level for all patches; Simpson and Shannon diversity index (SHDI, SIDI, MSIDI, SHEI, SIEI and MSIEI)of the metrics were calculated in order to diversity and uniformity analysis of land uses types. The Shannon index of diversity (SHDI, see Shannon and Weaver 1949) is the most widely used index for diversity evaluation. This index, ranging in theory from 0 to infinity, estimates the average uncertainty in predicting which land cover type a randomly selected subunit of the landscape will belong to. Also widely used, the Simpson index (SIDI, see Simpson 1949), Producing values from 0 to 1, Simpson's index defines the probability that two equalized subs-units of the landscape, selected at random, belong to different cover types.

Both these indices of diversity combine evaluations of richness and evenness. The landscape metrics are shown in Table 1.

They increase under situations where the number of land cover types (landscape richness) increases, or the equitability of distribution of

\section{Landscape level analysis}

Table 1. Description of metrics used in landscape and class level analysis.

\begin{tabular}{|c|c|c|c|}
\hline $\begin{array}{c}\text { Character Formula and } \\
\text { abbreviations }\end{array}$ & Description & Unit & $\begin{array}{c}\text { Range } \\
\text { ofchanges }\end{array}$ \\
\hline \multicolumn{4}{|c|}{ Landscape and class level analysis } \\
\hline$N P=n$ & Number of patches & - & $\mathrm{NP}>0$ \\
\hline$P L A N D=P_{i}=\frac{\sum_{j=1}^{a} a_{i j}}{A}(100)$ & Area fraction with patches & $\%$ & $0<$ PLAND $<100$ \\
\hline$P D=\frac{n_{i}}{A}(10000)(100)$ & $\begin{array}{l}\text { Number of patches per } 100 \\
\text { ha }\end{array}$ & \# & $\mathrm{PD}>0$ \\
\hline$E D=\frac{\sum_{k=1}^{m} e_{i k}}{10000)}$ & $\begin{array}{l}\text { Edge density, wherei is the } \\
\text { land use classes andk is for } \\
\text { edge length }\end{array}$ & $\begin{array}{l}\text { Meter per } \\
\text { hectare }\end{array}$ & $\mathrm{ED}>0$ \\
\hline
\end{tabular}

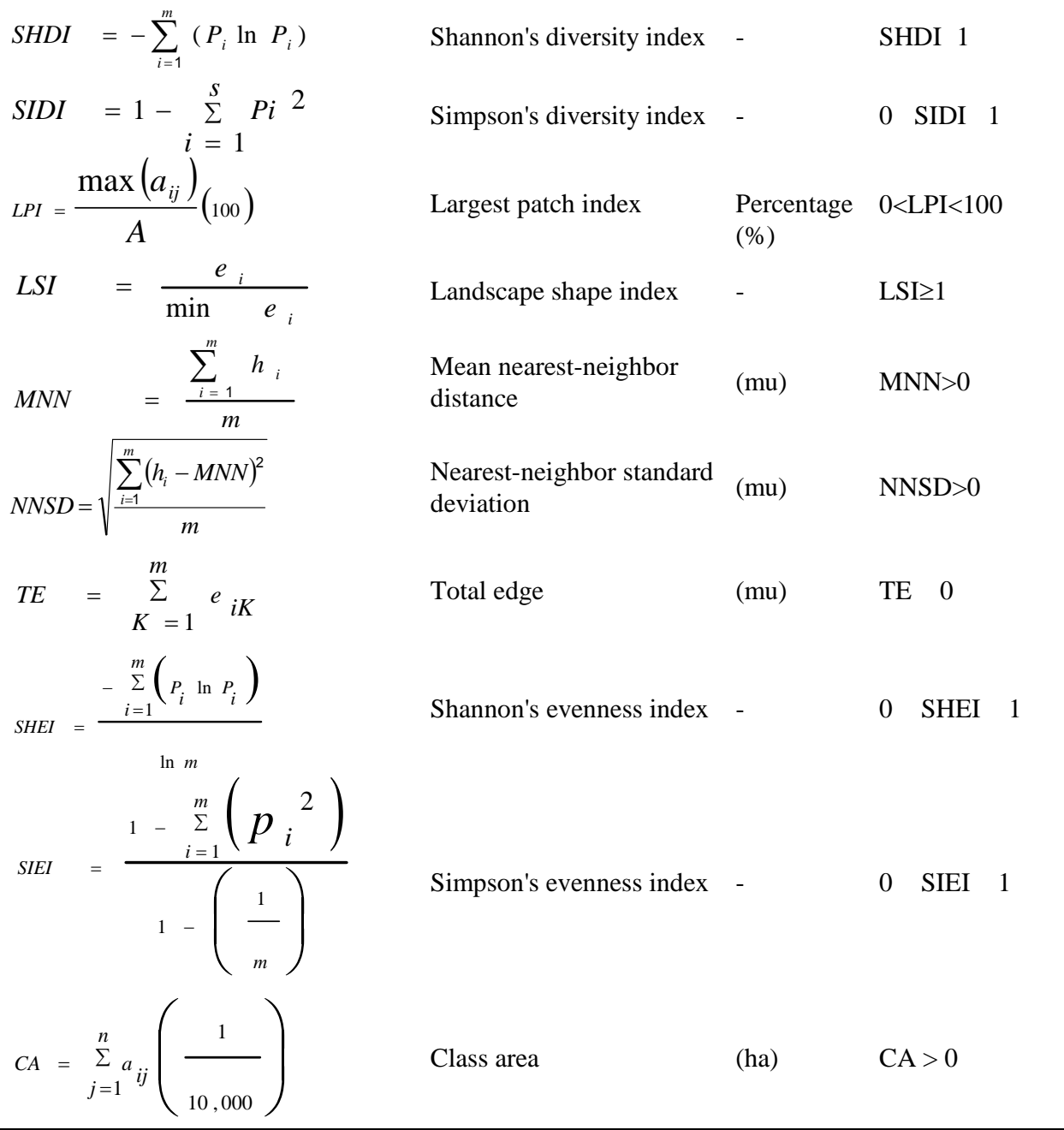

land amongst the various cover types (landscape evenness) increases, or both (Nagendra 2002). 


\section{RESULTS AND DISCUSSION}

According to the analysis of land use patches in the Zagros Mountains region (Figure 1B), agricultural patches observed more in the east of Kurdistan province, forest patches in the west and rangelands in the central part as north-south strips are distributed. The map of land use distribution illustrated in Figure 1B, which variety of land uses and patches are detectable.

\section{Metric analysis of class level}

Metric analysis of class level with calculating percent of land use metrics, patch density, average of patches size, the largest size of patches, metric of landscape shape and the average landscape patches had done. As shown in Table 2, the density of agriculture patches (PD) in this region is higher than other land uses, and the forest, rangeland users, and the land without cover (bare land) were the next of orders, respectively. According to Table 2, and the number and distribution of patches of urban and residential areas in the landscape level, the close relationship and intimately between nature and humans there are in level and should be considered in planning sustainable land management. According to Table 2, the largest land use area and the greatest number of patches, respectively, recorded in agricultural land, Rangelands and forest. Bare lands including no covered area have minimum area and river lands showed lowest number have in this level compared to the other land uses. The number of residential areas patches (urban patches) in this level had shown in Table 2, according to this metric and area of this province, high relation between human community's presence and change in nature cane revealed.

Analysis of the total land area fraction (Table 2, PLAND) and total edge (Table 2, TE) metrics among land uses in the Zagros Mountains region showed that according to the percentage cover metrics, agricultural lands, rangeland and forested area in this region had covered the largest area, respectively.

As we illustrated in Figure 3, statistical characteristics of areas related metric showed the main area of land use
Table 2. Patches structure related metrics in the class leve

\begin{tabular}{lllllllll}
\hline \multirow{2}{*}{$\begin{array}{c}\text { Land use types } \\
\text { (Map unit) }\end{array}$} & \multicolumn{8}{c}{$\begin{array}{c}\text { Zagros Mountains region,map 1 : 250,000 scale } \\
\text { metrics in the level of class }\end{array}$} \\
\cline { 2 - 8 } & CA (ha) & $\begin{array}{l}\text { NP } \\
(\mathbf{n})\end{array}$ & $\begin{array}{l}\text { PD } \\
(\mathbf{m})\end{array}$ & $\begin{array}{l}\text { LPI } \\
\mathbf{( \% )}\end{array}$ & $\begin{array}{l}\text { ED } \\
(\mathbf{m})\end{array}$ & TE $(\mathbf{m})$ & LSI & PLAND(\%) \\
\hline Forest & 373432.12 & 223 & 0.01 & 6.24 & 3.96 & 7309130 & 14.91 & 12.68 \\
Pastures & 1243724 & 919 & 0.034 & 24.36 & 10.41 & 24260814 & 21.68 & 41.28 \\
Agricultural land & 1268342 & 1560 & 0.038 & 32.26 & 10.35 & 31503691 & 20.44 & 45.87 \\
Bareland & 4789.58 & 38 & 0.0003 & 0.01 & 0.01 & 129204.7 & 1.67 & 0.01 \\
Residential & 6169.49 & 30 & 0.0007 & 0.06 & 0.04 & 204448.5 & 2.05 & 0.1 \\
Rivers & 8382 & 13 & 0.0007 & 0.04 & 0.04 & 255599.6 & 2.28 & 0.06 \\
\hline
\end{tabular}

Table 3. Mean ( \pm S.E.), weighted mean, Median and Range of Euclidean distance the nearest neighbor metric in class level in the Zagros Mountains region in the west of Iran

\begin{tabular}{lllll}
\hline \multicolumn{1}{c}{ Land uses } & \multicolumn{1}{c}{ Mean $(\mathbf{k m})$} & $\begin{array}{c}\text { Weighted } \\
\text { mean }(\mathbf{k m})\end{array}$ & \multicolumn{1}{c}{ Median } & Range \\
\hline Forest & $1.83 \pm 2.8$ & 0.45 & 0.50 & 14.65 \\
Rangelands & $0.51 \pm 0.62$ & 0.12 & 0.26 & 3.95 \\
Agricultural area & $0.43 \pm 086$ & 0.10 & 0.20 & 7.78 \\
Other land uses $^{\mathrm{a}}$ & 120.49 & 120.49 & 120.49 & 0 \\
Total, allland uses & $123.26 \pm 10.4$ & 121.16 & & \\
\hline
\end{tabular}

Note: ${ }^{a}$ Other land uses including residential areas, bare lands and rivers.

Table 4. Statistical characteristic of metrics of land uses patches in landscape level in the Zagros Mountains region Map with 1:1000000 scale

\begin{tabular}{lll}
\hline Symbol & FRAGSTATS metrics & $\begin{array}{c}\text { FRAGSTATS } \\
\text { statistics }\end{array}$ \\
\hline TE & Total edge(mu) & 63762887.13 \\
PR & Patch Richness (No unit) & 6 \\
PRD & Patch Richness Density (Meter In 100hectares) & 0.002 \\
RPR & Relative Patch Richness (\%) & 100 \\
CA & Class area (ha) & 2904839 \\
PN & Patch number (No unit) & 2783 \\
PD & Patch density (Meter In 100hectares) & 0.08 \\
LPI & Largest patch index (\%) & 32.26 \\
ED & Edge density (Meterper hectare) & 13 \\
LSI & Landscape shape index (No unit) & 17.38 \\
AREA_MN & Mean patch area (mu) & 67.35 \\
AREA_AM & Mean weighted patch area (mu) & 50776.53 \\
AREA_MD & Median patch area (mu) & 1117.72 \\
AREA_RA & Range in patch area (mu) & 92317.42 \\
AREA_SD & Standard deviation in patch area (mu) & 7450.16 \\
AREA_CV & Coefficient of variation in patch area (mu) & 666.54 \\
ENN_MN & Mean patch distance (mu) & 1549.36 \\
ENN_AM & Mean distance -weighted patch (mu) & 221.14 \\
ENN_MD & Median patch distance (mu) & 249.93 \\
ENN_RA & Range in patch distance (mu) & 99913.08 \\
ENN_SD & Standard deviation in patch distance (mu) & 8910.04 \\
ENN_CV & Coefficient of variation in patch distance (mu) & 575.07 \\
\hline & &
\end{tabular}

patches in agricultural, pasture and forest land uses through the province was higher in comparison with other land uses. The range of mean area variation in rangelands and forest land use patches was more than the mean of other land uses. This fact means the patches of rangelands and forestry had composed from the changing area and human based disturbances and interference in this land use was considerably over the time. 


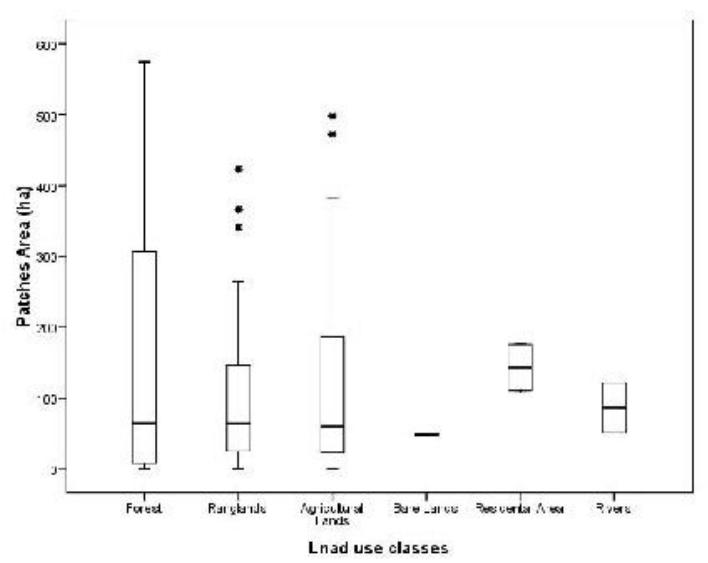

Figure 3.Statisticalcharacteristic of land use area metrics in class levels.

The values of the statistical metric of the Euclidean distance between the patches showed land use of the river, residential areas and rangelands patches had a high value in study area respectively (Table 3 ). Also given land use patches encompass the greatest value of the mean, weighted mean and the Euclidean median of distance between the patches, respectively. Analysis the statistical characteristics of the standard deviation and coefficient of variation Euclidean distance metrics among the land use patches revealed that the values of these metrics for residential and pasture land uses had the highest value.

\section{Metric analysis at landscape level}

In this analysis, the total area of the Zagros Mountains region assessed as an integrated landscape. Table 4 showed the differences in metric values and the spatial distribution of land uses in landscape level (province). Comparable results of land use metrics in landscape level showed the most of the patches were composed of small patches of land use at the provincial level (Table 4).

We had calculated diversity index for land use patches, results showed this value in the province was around one that means a diversity of land use area in this region high is high. Variation in diversity index had shown in Figure 4.

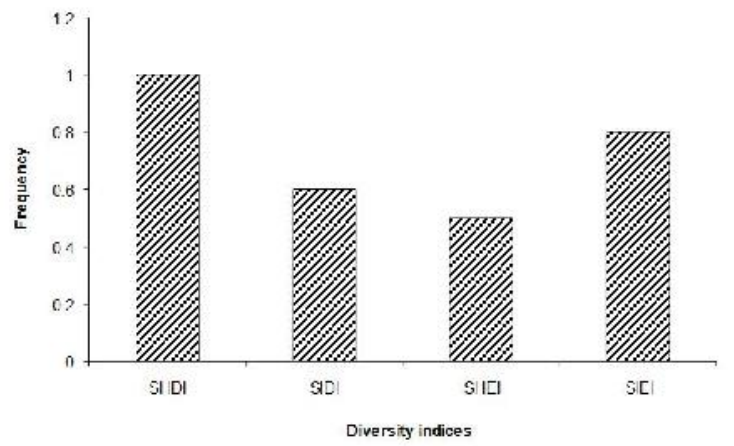

Figure 4. Frequency of diversity indexes among some different land use patches in landscape level.

\section{Discussion}

Different factors affect the formation and arrangement of patches in a landscape including: processes of geology, topography, soil, etc. (Natural) and various human interventions (artificial). The quantitative metric can be considered as a suitable tool for identifying and understanding the land use changes As the results showed the concept of using metrics and spatial pattern of land use patches are based on fragmentation are by different land uses which are the most important index to evaluate human based changes and variation in the nature and natural landscapes (Botequilha-Leitão and Ahern 2002).

Different regions of the earth according to the different ecological condition, different climatic and economicsocial processes and human activities showed variable land use patterns. Removing the large patches of agricultural area cause to fragmentation and create human made patches that this is an effective phenomenon of the life cycle of the Earth. In this area density of patches and distance between natural patches such as forest revealed human based disturbances caused to change and fragmentation of land uses.

The use of concepts of landscape ecology in the many scopes and issues such as design of landscape, environmental impact assessment, ecosystem management, rural development is applicable. Landscape concepts and metrics in the land use planning for describing and explaining the communication-pattern model process is required (Foresman et al. 1997; Gulink et al. 2001). For example, Landscape concepts and metrics can be used for the design appropriate different land uses.

As the results revealed the density of agricultural land use patches was greater than other land uses in this region. However the density of forest land is lower than other land uses in at the provincial level, the reason is that the natural forests just cover western parts of the province as well rangelands distributed more on north-south strip in the central parts of the provinces. According to the composition and structure of metrics, it can be concluded that from the western region of provinces to east natural land use patches is going to reduce and artificial land uses are going to increase. In landscape level, the ecological processes and human activities have an important role in the formation spatial pattern of the landscape, so that can be expressed that the spatial patterns, caused by ecological processes, and in other hand ecological processes, can reflect changes in landscape. Function of landscapes is highly affected by with the landscape structure Therefore formation of land uses is strongly related to the structure and function of the landscape (Zhang et al. 2008).

Accordingly, and considering to this fact that in this province of west to east precipitation decrease and physiographical properties is better and in instead residential areas, good soil, etc. That makes situation suitable for human communities' establishment and farming. This issue very well shows the effects of ecological processes and in following those human based factors on construction of the structure and composition of landscapes. Number of patches metric analysis revealed the vulnerability of each ecosystem in this region (the natural, 
semi-natural and artificial land uses) can be classified, so that an increasing number of land use patches caused to increase the vulnerability of land use patches, and conversely whatever those numbers of patches are low, threshold of land uses vulnerability is high. According to this fact and the results of this study the agricultural and rangeland uses are more exposed to the vulnerability in comparing to the other natural land uses. As well by using total edge metric and shape complexity of each land uses level of each land uses exposure with surrounding land uses can be calculated, therefore whatever value of this metric is more, land uses the desired (especially about the natural and sustainable land uses) are more vulnerable to changes, according to this analysis, agriculture and pasture land uses are susceptible to the vulnerability and are more sensitive ecosystems, and should be manage these areas more cautious in future planning. As mentioned, patchy structure is composed from many small patches and fragmentation has been extraordinary. In this research to discover the distribution and spatial distribution of land use patches Simpson and Shannon diversity index as metrics were used, if the amount of this metric is more than 1, univalve distribution and if equal is of a random, and if is less than the form of a have uniform distribution, as are observed, this amounts to Zagros Mountains region is calculated nearly 1 and equal to 1 , thus can be expression land users the distribution of patches in the Zagros Mountains region is greater random and uniform.

Results showed that this region occupied by heterogeneity mosaics of land uses patches including, patches of natural, semi natural and human made land uses. Natural patches are including rivers, bare land, forest and rangeland. Patches of semi-natural area including agricultural land and human made land uses the patches such as residential area. Range of patch area changes in agriculture, pasture and forest land uses in landscape level is high and distribution of this patch in the provinces is regional.

In the Zagros Mountains region, despite a high density of agricultural and rangeland uses (semi-the natural and the natural patches) have a high potentials to convert this land uses into sustainable ecosystems (forest and integrated agriculture), that needed to suitable administrative procedures and policy control.

\section{CONCLUSION}

Landscape metrics can be useful in the management of natural resources and land uses sustainable. But while these metrics are used for future planning as the decision support system, should be intensified and a batch that the each metric that belongs to be determined. One of the advantages of assessment patches using the landscape metric is awareness from extent of intensity of landscape in the shortest possible time using the digital data. On the other hand, in this method for the destruction of determine hierarchy between work units, the minimum expertise is applicable, that the by using results obtained from the hierarchy of destruction between work units can be managed land uses according to the nature and environmental condition, so we suggest in planning land use in this area we need to assess this area according to the metrics.

\section{REFERENCES}

Anon. 2000. Weather Report from Kurdistan. Jamab Consultant Engineers Company, Iran.

Bell S. 1999. Landscape: pattern, perception and process. E and F SPON, London.

Botequilha-Leitao A, Ahern J. 2002. Applying landscape ecological concepts and metrics in sustainable landscape planning. Landsc Urban Plan 59 (2): 65-93.

Botequilha-Leitao A, Jozeph M, Ahern J. 2006. Measuring landscapes: A planner's handbook. Island Press, Washington, D.C.

ESRI A. 1992. Understanding GIS: the ArcInfo method. Environmental Systems Research Institute, Redlands, CA.

Foresman TW, Pikkett STA, Zipperer W C. 1997. Methods for spatial and temporal land use and land cover assessment for urban ecosystems and application in the greater Baltimore-Chesapeake region. Urban Ecosyst 1 (4): 201-216.

Forests, Range and Watershed Management Organization, I.R. Iran. 2010. Map of land use Kurdistan province, Iran. Forests, Range and Watershed management Organization, I.R. Iran, Tehran.

Gulink H, Mugica M, De Lucio J V, Atauri J A. 2001. A framework for comparative landscape analysis and evaluation based on land cover data with an application in the Madrid region (Spain). Landsc Urban Plan 55(4): 257-270.

Herzog F, Lausch A. 2001. Supplementing land-use statistics with landscape metrics: Some methodological consideration. Environ Monit Assess 72 (1): 37-50.

Ingegnoli V. 2002. Landscape Ecology: A widening foundation. Springer, New York.

Karami A. 2011. Investigation on the Metrics of the Forest Regeneration Patches for Sustainable Forest Management. [M.Sc. Thesis]. Faculty of Natural Resources, University of Tehran, Karaj, Iran

Lausch A, Herzog F. 2002. Applicability of landscape metrics for the monitoring of landscape change: issues of scale, resolution and interpretability. Ecol Indicat 2 (1-2): 3-15.

Marvie-Mohadjer MR. 2005. Silviculture and Forest Tending. University of Tehran press, Tehran.

McGarigal K, Marks BJ. 1994. FRAGSTATS: spatial pattern analysis program for quantifying landscape structure, version 2. Forest Science Department. Oregon States University. Corvallis, OR.

McGarigal KB, Marks BJ. 1995. Fragstats: Spatial pattern analysis program for quantifying landscape structure. Reference manual. Forest Science Department. Oregon State University. Corvallis, OR.

Nagendra H. 2002. Opposite trends in response for the Shannon and Simpson indices of landscape diversity. Appl Geogr 22: 175-186.

Naveh Z, Liberman A. 1984. Landscape ecology: theory and application. Springer, New York.

Razmara H A. 2005. Culture and Geography of Iran. Tehran Geographic Circle of Army Staff 5: 13-133.

Rogers CA. 1993. Describing landscapes: Indices of structure. [M.Sc. Thesis], Simon Fraser University, Burnaby, British Columbia.

Shamekhi T. 2007. Agroforestry. Tehran University press, Karaj. [Persian].

Shannon CH, Weaver W. 1949. The mathematical theory of communication. University of Illinois Press, Illinois.

Simpson EH. 1949. Measurement of diversity. Nature 163: 688.

Wegener M. 1994. Operational urban models: State of the art. J Amer Plan Assoc 60 (1): 17-29.

Wu J. 2000. Landscape ecology: Pattern, process, scale and grade. Higher Education Press, Beijing.

Xiao DN, Zhong LS. 1998. Ecological principles of landscape classification and assessment. Chinese J Appl Ecol 9: 217-231 [Chinese].

Zhang HY, Ni JR. 2001. Discussion on the space methods of the city space ecology adjusts and control. City Plan Rev 25 (7): 15-18.

Zhang Q, Ban Y, Liu J, Shu Q, Hu Y. 2008. Analysis of landscape dynamics in shanghais using landscape metrics: Effects of spatial resolutions. The International Archives of the Photogrammetry, Remote Sensing and Spatial Information Sciences, Vol. 37. Part B6b, Beijing, 2008. 